\title{
Indicadores de gestão ambiental no auxílio à administração pública no estado do Ceará
}

Este estudo objetivou caracterizar geoambientalmente os municípios do Ceará por região de planejamento. Adotou-se a construção de índice agregado: Índice de Gestão (IG) somando 19 indicadores, considerando a gestão para o meio ambiente e o Índice Gestão à Seca (IGS) com 17 indicadores que trata da adoção de medidas, extraídos da pesquisa Perfil dos Municípios Brasileiros (IBGE), ano 2017. Os municípios possuem Conselhos Municipais Ambientais, exceto Martinópole não possuindo estrutura nenhuma de gestão ambiental. Os índices de gestão e de adoção de medidas à seca possuem baixo e médio baixo desenvolvimento em gestão, respectivamente. Conclui que as regiões Grande Fortaleza e Maciço de Baturité apresentou um dos piores resultados quanto ao índice de gestão à seca e Sertão dos Inhamus apresentou a melhor gestão ambiental.

Palavras-chave: Gestão Ambiental; Indicadores; Ceará.

\section{Environmental management indicator in support to public administration in the state of Ceará}

\begin{abstract}
This study aimed to geoenvironmentally characterize the municipalities of Ceará by planning region. The construction of an aggregate index was adopted: Management Index (IG) adding 19 indicators, considering the management for the environment and the Dry Management Index (IGS) with 17 indicators that deals with the adoption of measures, extracted from the survey Brazilian Municipalities (IBGE), year 2017. The municipalities have Municipal Environmental Councils, except Martinópole having no environmental management structure. The rates of management and adoption of drought measures have low and medium low development in management, respectively. It concludes that the regions Grande Fortaleza and Maciço de Baturité presented one of the worst results regarding the drought management index and Sertão dos Inhamus presented the best environmental management.
\end{abstract}

Keywords: Environmental Management; Indicators; Ceará.

Topic: Planejamento, Gestão e Políticas Públicas Ambientais

Reviewed anonymously in the process of blind peer.
Received: 04/04/2021

Approved: $28 / 04 / 2021$
Kaliny Kélvia Pessoa Siqueira Lima (it) Universidade Federal do Ceará, Brasil http://lattes.cnpq.br/7481962526311933 http://orcid.org/0000-0002-2572-6292 kalinylima61@gmail.com

Vládia Pinto Vidal de Oliveira

Universidade Federal do Ceará, Brasil http://lattes.cnpq.br/5787834301134358

http://orcid.org/0000-0001-7756-9009 vladia.ufc@gmail.com
Referencing this:

LIMA, K. K. P. S.; OLIVEIRA, V. P. V.. Indicadores de gestão ambiental no auxílio à administração pública no estado do Ceará. Revista Ibero Americana de Ciências Ambientais, v.12, n.4, p.642-658, 2021. DOI: http://doi.org/10.6008/CBPC2179-6858.2021.004.0050 


\section{INTRODUÇÃO}

O Estado do Ceará tem uma população masculina contabilizada em 4.118.066 indivíduos, ultrapassada pela população feminina, que ronda os 4.329.989; 93\% do território do Ceará, que em termos político-administrativos conta com 184 municípios, está inserido na região do semiárido e tem um clima preponderantemente tropical quente, o que o torna vulnerável à ocorrência de períodos consideráveis de seca, devido à pouca precipitação pluvial. Esta situação reflete-se na economia, sendo este, um dos estados mais carenciados do país.

Este trabalho tem como objetivo geral desenvolver e aplicar indicadores de gestão e ações de medidas que possam auxiliar no diagnóstico ações de implementação e auxiliar em políticas públicas de gestão de impacto direto na redução dos efeitos advindos da seca.

Especificamente pretende-se: i) caracterizar geo-ambientalmente os municípios do Estado do Ceará por região de planejamento; ii) identificar dentre as áreas de planejamento, o território semiárido e os municípios que mais sofreram com evento seca nos últimos 4 anos; iii) analisar, comparar e interpretar os dados e resultados obtidos através da aplicação de indicadores de gestão e ações de medidas nas regiões de planejamento do cearense.

Este estudo utiliza de um método empregando um amplo conjunto de indicadores de gestão. Ao todo somando 19 indicadores voltadas a analisar a gestão estadual no combate à seca e 17 indicadores voltados a analisar a adoção de medidas do governo estadual no combate à seca.

O foco principal da utilização destes indicadores é investigar como a gestão trata os efeitos da seca nas regiões semiáridas do Ceará. Além do mais, este estudo busca incentivar projetos e/ou programas de gestão, compatíveis com as especificidades locais e com a cultura de cada população, objetivando melhorar os métodos de convivência com a seca e suas adversidades. Desta forma, o Poder Público pode fortalecer as medidas de proteção e prevenção frente às vulnerabilidades e ao fenômeno da seca com alternativas menos dispendiosas e mais eficazes.

Segundo Mendonça (2004), problemas que envolvem situações conflituosas, decorrentes da interação entre a sociedade e a natureza, deve ser trabalhado por meio de pesquisas em conformidade com a geografia socioambiental do local e que explicitem a degradação de uma ou de ambas.

Este trabalho pretende seguir os principais critérios para avaliar o potencial da pesquisa, conforme Sampieri et al. (1991): conveniência, relevância social, implicações práticas, valor teórico e utilidade metodológica. Alvarenga et al. (2011) ressalta que a interdisciplinaridade busca responder a problemas gerados pelo próprio avanço da ciência moderna disciplinar, é onde se faz a relação entre os saberes, o encontro entre o teórico e o prático, o filosófico e o científico, a ciência e a tecnologia, apresentando-se como um saber que responde aos desafios do saber complexo.

\section{REVISÃO TEÓRICA}

De acordo com Melo (2008, citado por ROSENDO, 2014), o clima da porção semiárida brasileira é 
caracterizada por baixas precipitações pluviométricas, mal distribuídas no tempo (fortemente concentrado em quatro meses entre os meses de fevereiro-maio) e no espaço, e elevados níveis de evaporação, o que gera um déficit hídrico e consequentemente elevação do índice de aridez. As tipologias de solos são rasas e pouco desenvolvidas, haja vista o baixo nível de intemperismo químico das rochas. As limitações hídricas da região impõem a necessidade de um adequado manejo do solo, manutenção de sua cobertura vegetal, com o intuito de evitar a erosão e a adoção de práticas conservacionistas que possibilitem a manutenção do equilíbrio.

No Brasil, o semiárido já recebeu diversas denominações, como Sertão e Nordeste das Secas. Segundo Silva (2006, citado por ROSENDO, 2014), esse território abrange cerca de 1.133 municípios com uma área de $969.589,4 \mathrm{~km}^{2}$, correspondendo a quase $90 \%$ da região Nordeste e mais a região setentrional de Minas Gerais. Com uma população de 21 milhões de pessoas, o semiárido é marcado pelo abandono governamental.

O Estado do Ceará sofre, entre outros, sérios problemas de estiagem que ocorrem na região Nordeste do Brasil, fenômenos que, à luz do conhecimento científico atual, está intimamente ligado à circulação atmosférica de larga escala (WALKER, 1928) causando sérios transtornos às populações nordestinas, principalmente àquelas que vivem nos sertões dos Estados incluídos no Polígono das Secas ${ }^{1}$.

O clima temperado e seco, com escassa variação de temperatura, tal qual no semiárido nordestino, torna as chuvas raras no arquipélago; alternando períodos sem chuvas com outros em que esta desaba toda em um curto espaço de tempo. Ao longo dos séculos, prevaleceu no país a ideia de que o semiárido seria um lugar inóspito, sem possibilidades de desenvolvimento e fadado ao atraso. Hoje em dia, está cada vez mais evidente que essa noção faz parte de uma ideologia falaciosa que tem sido útil para legitimar ações políticas desenhadas para favorecer a reprodução política de uma minoria elitista.

O espaço geográfico é dinâmico sendo alvo de mudanças geossocioeconômicas ao longo do tempo, como, por exemplo, as intervenções relacionadas à atração de empresas, à ampliação de serviços públicos ou mesmo de infraestrutura, criando fixos e aumentando a rede de fluxos, proporcionando assim maior integração entre regiões.

As regiões de planejamento possuem quatorze territórios, distinguindo áreas que antes eram agregadas no modelo das macrorregiões, a exemplo das regiões da Ibiapaba, Sobral, Litoral Leste, Vale do Jaguaribe, Cariri, Centro Sul, Litoral Norte e Litoral Oeste/Vale do Curu. Este detalhamento possibilita o planejamento regional de forma mais eficaz ao consentir o delineamento das vocações regionais de cada região de forma individualizada.

Menciona-se, ainda, que o atual Plano de Governo determina a diretriz de revisão do recorte territorial das unidades de planejamento para a integração das diversas políticas públicas, a partir dos treze territórios de identidade rural e das vinte microrregiões de planejamento do estado do Ceará.

\footnotetext{
${ }^{1} \mathrm{O}$ Polígono das Secas foi criado por Lei Federal em 7 de janeiro de 1936. Após sucessivas mudanças ao longo tempo, alterando sua delimitação e instituindo particularidades, o Decreto-Lei de no 63.778, de 11 de dezembro de 1968, delegou à extinta Superintendência do Desenvolvimento do Nordeste (Sudene) a competência de declarar os municípios pertencentes ao Polígono das Secas. Foi com a extinção da Sudene que a responsabilidade pela definição do Semiárido passou para o Ministério da Integração Nacional, o qual deu nova delimitação ao Polígono das Secas, em 2005.
} 
Conforme IPECE (2006), o termo região está, normalmente, associado a um determinado espaço físico, particularizado por determinadas características semelhantes, tais como: condições geográficas, socioeconômicas, culturais, étnicas etc.

Freitas (2009) afirma que uma região se refere a uma área contínua com características de homogeneidade relacionadas ao domínio de determinados aspectos, sejam eles, naturais e/ou construídos, econômicos e/ou políticos. Esses aspectos personalizam e diferenciam uma região das demais. A delimitação regional aponta quase que invariavelmente para três tipos de critérios que estruturam o conceito de regionalização: polarização, homogeneidade e planejamento.

Conforme Souza (2000, citado por LIMA, 2014), as unidades geoambientais são integradas por vários elementos que mantêm relações mútuas entre si, e são continuamente submetidas aos fluxos de matéria e energia. Assim, estas unidades são o produto de uma matriz de fatores ambientais relativos ao suporte (condições geológicas e geomorfológicas), ao envoltório (condições hidrológicas e climáticas) e à cobertura (solos e cobertura vegetal) de uma determinada região, apresentando características de vulnerabilidades e potencialidades que permitem a sua utilização para o planejamento territorial.

\section{METODOLOGIA}

Indicadores são apresentados como um valor estatístico em si, desvirtuando o sentido do próprio conceito: um indicador expressa algo que ele mesmo não é, ou seja, ele exprime apenas parcialmente determinado aspecto; ele é somente uma espécie de representante de um determinado aspecto de uma realidade bem mais complexa (SIEDENBERG, 2003). Logo, os indicadores não podem ser percebidos como um fim em si mesmo; são, na melhor das hipóteses, instrumentos analíticos auxiliares, úteis para sistematizar e representar uma realidade muito complexa.

O estudo realizado por Bhattacharya et al. (2007) adotou o procedimento de agregação simples, através de médias geométricas ou de médias aritméticas, com o intuito de analisar os mais diversos indicadores normalizados ${ }^{2}$, que buscam como produto um índice de vulnerabilidade à seca, que pode ser comparado entre outras áreas de estudo.

No tocante da utilização das médias (aritmética e geométrica), o processo de agregação simples é amplamente utilizado no desenvolvimento de vários índices de desenvolvimento humano do Programa das Nações Unidas para o Desenvolvimento (PNUD) e se configura como uma ferramenta de grande importância para a avaliação dos mais diversos tipos de gestão.

Em se tratando do cálculo dos índices, diversas são as metodologias encontradas nos estudos concernentes ao tema. As variações vão desde o número de dimensões e critérios considerados até o cálculo dos índices socioeconômico.

Para tornar possível uma análise estatística mais rigorosa e uma melhor aplicabilidade dos resultados optou-se por construir índice agregado: o Índice de Gestão (IG) foi elaborado considerando a gestão com o

\footnotetext{
${ }^{2}$ Entendem-secomoindicadoresnormalizados,osvaloresdosindicadoresexpressosemumaescalaque varia entre o número 0 (zero) e número 1 (um) 
olhar para o meio ambiente e o Índice Gestão à Seca (IGS) que trata do nível de adoção de medidas à seca em cada município como forma direcionar a administração pública em decisões na convivência aos efeitos vivido nas áreas semiáridas, no qual foram analisados a partir de um conjunto de indicadores extraídos da pesquisa Perfil dos Municípios Brasileiros, publicada pelo IBGE, ano de referência 2017, e expostos no Quadro 2.

Quadro 1: Caracterização das Regiões de Planejamento do Estado do Ceará.

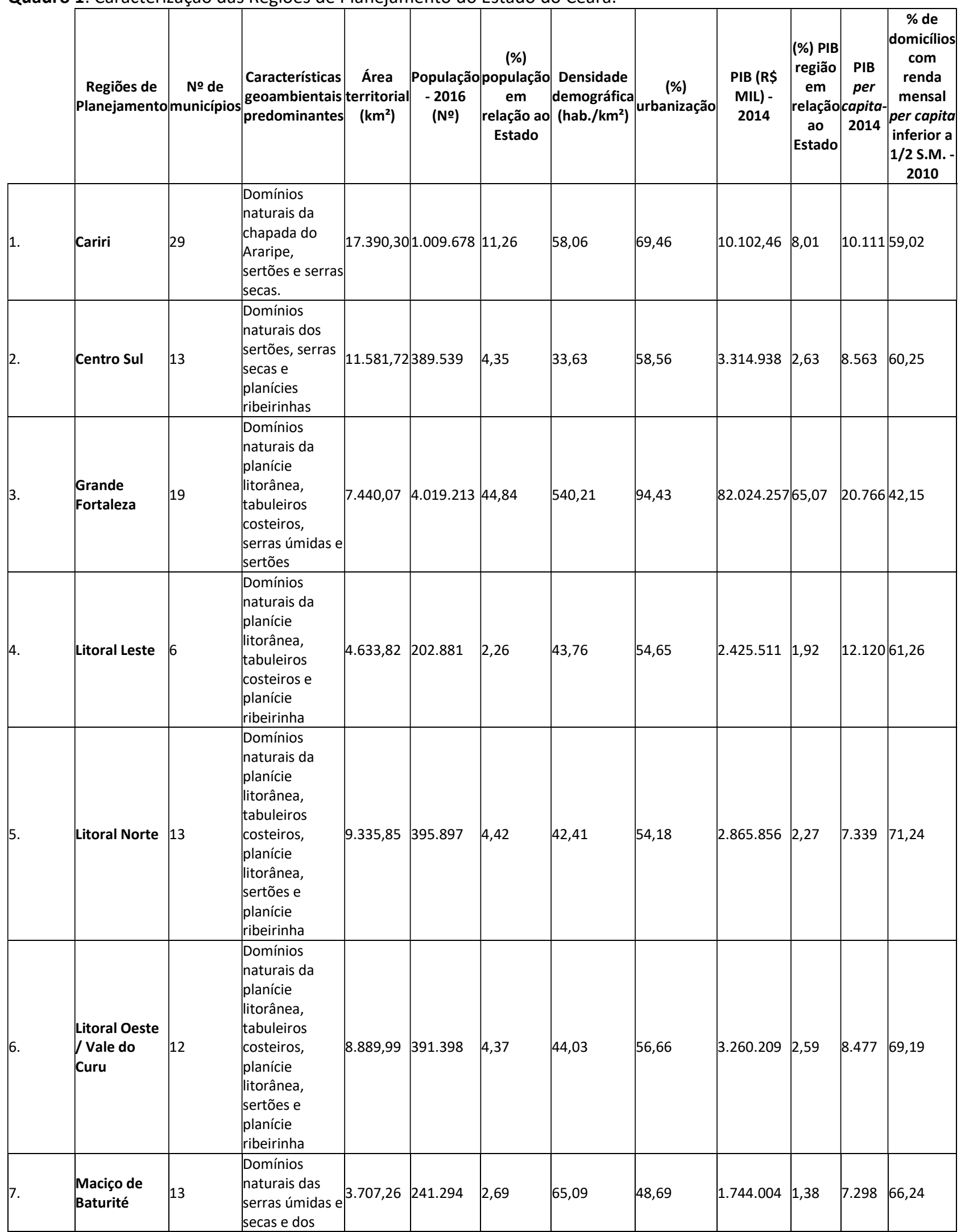




\begin{tabular}{|c|c|c|c|c|c|c|c|c|c|c|c|c|}
\hline & & & sertões & & & & & & & & & \\
\hline 8. & $\begin{array}{l}\text { Serra da } \\
\text { lbiapaba }\end{array}$ & 9 & \begin{tabular}{|l|} 
Domínios \\
naturais do \\
Planalto da \\
Ibiapaba e dos \\
sertões
\end{tabular} & $5.697,30$ & 354.952 & 3,96 & 62,3 & 51,95 & 2.830 .116 & 2,25 & 8.076 & 65,86 \\
\hline 9. & $\begin{array}{l}\text { Sertão } \\
\text { Central }\end{array}$ & 13 & \begin{tabular}{|l|} 
Domínios \\
naturais dos \\
sertões e serras \\
secas
\end{tabular} & $16.014,77$ & 391.005 & 4,36 & 24,42 & 56,1 & 2.961 .838 & 2,35 & 7.650 & 63,16 \\
\hline 10. & $\begin{array}{l}\text { Sertão de } \\
\text { Canindé }\end{array}$ & 6 & \begin{tabular}{|l|} 
Domínios \\
naturais dos \\
sertões e serras \\
secas
\end{tabular} & $9.202,52$ & 204.395 & 2,29 & 22,27 & 55,82 & 1.291 .374 & 1,02 & 6.367 & 68,11 \\
\hline 11. & Sertão Sobral & 18 & \begin{tabular}{|l|} 
Domínios \\
naturais dos \\
sertões, das \\
serras úmidas e \\
secas, e da \\
planície \\
ribeirinha
\end{tabular} & $8.528,07$ & 489.265 & 5,46 & 57,37 & 70,58 & 5.552 .490 & 4,4 & 11.510 & 60,26 \\
\hline 12. & $\begin{array}{l}\text { Sertão dos } \\
\text { Crateús }\end{array}$ & 13 & \begin{tabular}{|l|} 
Domínios \\
naturais dos \\
sertões e serras \\
secas
\end{tabular} & $20.594,40$ & 349.455 & 3,9 & 16,44 & 58,11 & 2.398 .967 & 1,9 & 6.877 & 65,24 \\
\hline 13. & $\begin{array}{l}\text { Sertão dos } \\
\text { Inhamus }\end{array}$ & 5 & $\begin{array}{l}\text { Domínios } \\
\text { naturais dos } \\
\text { sertões }\end{array}$ & $10.863,48$ & 134.776 & 1,5 & 12,41 & 46,28 & 942.654 & 0,75 & 7.029 & 67,14 \\
\hline 14. & $\begin{array}{l}\text { Vale do } \\
\text { Jaguaribe }\end{array}$ & 15 & \begin{tabular}{|l} 
Domínios \\
naturais das \\
planícies \\
ribeirinhas, da \\
chapada do \\
Apodi, da \\
planície \\
litorânia, dos \\
tabuleiros \\
costeiros e dos \\
sertões
\end{tabular} & $15.006,77$ & 389.375 & 4,34 & 25,95 & 58,61 & 4.339 .460 & 3,44 & 11.225 & 57,26 \\
\hline
\end{tabular}

Fonte: IPECE (2006).

Com o objetivo de agregar as informações referentes aos indicadores foram construídos dois índices: Índice de Gestão - IG e Índice de Gestão à Seca - IGS. O IG que é resultado da agregação de 19 indicadores buscou captar o grau de implementação de instrumentos auxiliadores da gestão nas preocupações que tange ao meio ambiente e o IGS que é a agregação de 17 indicadores, é um indicador de resultado que analisa o grau de implementação de ações e medidas voltadas à seca que podem auxiliar na tomada de decisão em melhorar as condições de convivência com o semiárido diante dos efeitos e riscos provocados pela seca, como mostra no quadro 2.

Quadro 2: Indicadores componentes dos índices de Gestão (IG) e à Seca (IGS).

\begin{tabular}{|l|l|}
\hline Indicadores de Gestão - IG & KK001 \\
\hline 1 - Caracterização do órgão gestor municipal & KK002 \\
\hline 2 - Número de funcionários Estatutários & KK003 \\
\hline 3 - Número de funcionários Celetistas & KK004 \\
\hline 4 - Número de funcionários somente comissionados & KK005 \\
\hline 5 - Número de Estagiários & KK006 \\
\hline 6 - Número de funcionários sem vínculo permanente & KK007 \\
\hline $\begin{array}{l}\text { - Em qual(is) área(s) temática(s) se deu(ram) essa(s) capacitação(ões): Estruturação da gestão municipal de meio } \\
\text { ambiente }\end{array}$ & KK008 \\
\hline 8 - Em qual(is) área(s) temática(s) se deu(ram) essa(s) capacitação(ões) :Recursos Hídricos & KK009 \\
\hline 9 - O município possui Conselho Municipal de Meio Ambiente ou similar & KK010 \\
\hline 10 - O Conselho Municipal do Meio Ambiente é Deliberativo & KK011 \\
\hline $\begin{array}{l}11 \text { - A área responsável pelo tema meio ambiente dispõe de recursos financeiros específicos para serem utilizados } \\
\text { no desenvolvimento de suas ações }\end{array}$ & \\
\hline
\end{tabular}


12 - O município possui Fundo Municipal de Meio Ambiente ou similar

KK012

13 - Quantidade de reuniões realizadas pelo Conselho Municipal de Meio Ambiente nos últimos 12 meses

14 - Legislação ou instrumento sobre gestão de bacias hidrográficas

15 - Legislação ou instrumento sobre adaptação e mitigação de mudança do clima

16 - Legislação ou instrumento de fonte de recursos nos últimos 12 meses do governo estadual

KK013

KK014

KK015

17 - Legislação ou instrumento quanto a serviços ambientais acerca de pagamento por ações/iniciativas que promovam a conservação e a recuperação ou melhoramento da quantidade e da qualidade dos recursos hídricos

18 - Legislação ou instrumento quanto à impactos ambientais e/ou processos/ações de maior ocorrência: Condições climáticas extremas (secas, enxurradas)

19 - Legislação ou instrumento à impactos ambientais e/ou processos/ações de maior ocorrência: Diminuição de vazão de algum corpo d'água

Indicadores de Gestão à Seca - IGS

1 - O município foi atingido pela seca nos últimos 4 anos

KK016

2 - Ano em que aconteceu a seca de maior impacto para o município

3 - No ano de seca de maior impacto para o município ocorreram: perdas financeiras

4 - No ano de seca de maior impacto para o município ocorreram: perdas humanas

5 - No ano de seca de maior impacto para o município ocorreram: perdas de animais

6 - No ano de seca de maior impacto para o município ocorreram: perdas ambientais

7 - No ano de seca de maior impacto para o município ocorreram: perda ou redução da produção agrícola

KK017

8 - No ano de seca de maior impacto para o município ocorreram: surgimento ou aumento de área de desertificação

9 - No ano de seca de maior impacto para o município ocorreram: concentração de poluentes na água exigindo ampliação na captação e no tratamento da água

KK018

KK019

10 - O que está sendo feito no município para evitar ou minimizar os danos causados pela seca: construção de cisternas

11 - O que está sendo feito no município para evitar ou minimizar os danos causados pela seca: construção de açudes

12 - O que está sendo feito no município para evitar ou minimizar os danos causados pela seca: construção de barragens

13 - O que está sendo feito no município para evitar ou minimizar os danos causados pela seca: construção de poços

14 - O que está sendo feito no município para evitar ou minimizar os danos causados pela seca: revegetação

15 - O que está sendo feito no município para evitar ou minimizar os danos causados pela seca: incentivo público à agricultura adaptada ao clima e solo da região, com sistemas de irrigação

16 - O que está sendo feito no município para evitar ou minimizar os danos causados pela seca: distribuição regular de água através de carros-pipa em épocas de estiagem (situações de emergência)

17 - O que está sendo feito no município para evitar ou minimizar os danos causados pela seca: ações de uso sustentável dos recursos naturais (fontes de energia eólica ou solar, planos de bacia, programas de conscientização e sensibilização, etc.)

EL001

ELO02

EL003

EL004

EL005

EL006

EL007

EL008

EL009

EL010

EL011

EL012

EL013

EL014

EL015

EL017

É necessário ressaltar que os índices não têm a pretensão de quantificar a intensidade do desenvolvimento, mas sim hierarquizar e comparar os municípios e a região de planejamento do Estado do Ceará de acordo com suas potencialidades no que tange a administração pública para gestão e ações; potencialidades estas que podem auxiliar na criação de condições necessárias para desenvolver um sistema de monitoramento da gestão em respostas a desastres como seca e seus efeitos.

Pelo fato de os indicadores selecionados para cada dimensão serem mensurados em diferentes unidades de medida e com diferentes amplitudes de variação, eles são transformados em medidas adimensionais com magnitude entre 0 e 1 , com o objetivo de uniformizar as medidas. Estas novas medidas podem ser definidas como indicadores padronizados a serem obtidos da seguinte forma:

$$
I_{p i}=\frac{I_{i}-I_{\min }}{I_{\max }-I_{\min }}
$$

Onde: $\mid p i=$ valor do indicador padronizado do município $i ; l i=$ valor do indicador do município $i ; \operatorname{lmin}=$ valor do limite inferior do indicador, Imax = valor do limite superior do indicador.

Os valores máximos e mínimos não são, necessariamente, valores encontrados entre os observados.

Podem ser valores de referência definidos a priori. Caso o indicador expresse um atributo negativo e se queira inverter esta lógica, os valores mínimos e máximos são invertidos. Atualmente, a metodologia considera os valores mínimos e máximos observados na série do período analisado, ou seja, valores observados no ano 
de 2017.

O procedimento acima é realizado para cada indicador de cada uma das dimensões incorporadas na construção do índice. Essa transformação permite que os indicadores sejam empregados como medidas relativas. No entanto, o emprego de limites inferiores e superiores fixos permite, também, analisar sua evolução ao longo do período. Obtidos os indicadores padronizados, para calcular o IG e IGS de cada município distribuídos na região de planejamento.

O cálculo do IG E IGS constou de três etapas, conforme Carvalho et al. (2013) e Lima (2014). Inicialmente considerou-se a natureza binária de cada indicador, sendo atribuído valor 1(um) à existência do componente de gestão e valor 0 (zero) à ausência. Em seguida foram atribuídas pontuações a cada município a partir da agregação dos pontos obtidos conforme equação 1 e, foram criados subíndices para cada dimensão por meio da expressão. A mesma expressão foi adotada no cálculo do Índice de Gestão - IG e do Índice de Gestão à Seca - IGS:

$$
S I G_{j p}=\frac{\sum_{i=1}^{n} E_{p i j}}{\sum_{i=1}^{n} E_{\text {maxi }} j}
$$

onde: $\mathrm{lj}=$ Índice observado no j-ésimo município; $\mathrm{E}_{\mathrm{ij}}=$ escore do i-ésimo indicador obtido pelo j-ésimo município ( 0 ou 1); Emaxi= escore máximo do $i$-ésimo indicador (no caso, 1$) ; i=1, \ldots \ldots ., p$, número de indicadores ( $p=19$ para o Índice de Gestão- IG e p = 17 para o Índice de Gestão à Seca - IGS); j = 1, .........., n, número de municípios ( $n=184)$.

$O$ valor de cada índice variou de 0 (nenhum dos instrumentos ou ações avaliados foi implementado pelo município) a 1 (todos os instrumentos ou ações avaliadas foram implementados pelo município). De outro modo, quando multiplicados por 100, os índices podem ser interpretados como o percentual de implementação dos instrumentos ou ações no combate à seca implementados pelo governo do estado do Ceará.

A avaliação final de cada índice obtido por cada município; nesta etapa da avaliação, são, portanto, classificados em quatro categorias de acordo com o valor dos índices obtidos (de seca e de adoção de medidas) e, recebem uma parametrização de acordo com o seu valor. Cada município pode ser posicionado em termos relativos posto como: $0,000 \leq$ [IGE; IG e IGS] $<0,500 \rightarrow$ baixo desenvolvimento da gestão; 0,500 $\leq$ [IGE; IG e IGS] $<0,650 \rightarrow$ médio-baixo desenvolvimento da gestão; 0,650 $\leq$ [IGE; IG e IGS] $<0,800 \rightarrow$ médioalto desenvolvimento da gestão; $0,800 \leq[$ IGE; IG e IGS] $<1,000 \rightarrow$ alto desenvolvimento da gestão.

A metodologia de categorização tomou como referencial teórico, sofrendo adaptações para o respectivo estudo, o trabalho sobre índice de desenvolvimento social dos municípios cearenses: IDS 20122015 realizado pelo Instituto de Pesquisa do Ceará - IPECE e divulgado e publicado por Assis et al. (2018).

\section{RESULTADOS E DISCUSSÃO}

A região de planejamento com maior número de municípios é a região do Cariri, com 29 municípios e a menor é a região do Sertão dos Inhamus, com apenas 5. A região do Cariri embora tenha apresentado a segunda maior área territorial e populacional, apresenta apenas a quinta PIB per capita do estado cearense, ficando atrás das regiões: Grande Fortaleza, Litoral Leste, Sertão Sobral e Vale do Jaguaribe, respectivamente. 


\section{Índice de Gestão - IG}

O índice de gestão trata de instrumentos de gestão pública voltados para o meio ambiente com variáveis pertinentes a estrutura organizacional, na formação órgão, comitês e/ou conselhos, além da formação e capacitação de pessoal; bem como ferramentas e dispositivos legais no intui de legislar quanto à práticas operacionais e disponibilidade de recursos.

Na tabela 1 podemos verificar a estatística descritiva do índice de gestão, onde podemos observar que o estado do Ceará possui um desvio padrão baixo, indicando que os resultados entre as regiões de planejamento circundam próximos a média. Já o coeficiente de variação, que trata do desvio padrão relativo, uma vez que apenas o resultado do desvio padrão não é o suficiente para caracterizar os dados, expressa um resultado com alta dispersão $(<30 \%)$ apresentando variáveis heterogêneas e categóricas de se fazer análises comparativas entre a variação de dados observados.

Tabela 1: Estatísticas descritivas do IG, por região de planejamento do Ceará (2017).

\begin{tabular}{|c|c|c|c|c|c|c|c|}
\hline Região de Planejamento & $\begin{array}{ll}\text { Total de } \\
\text { Municípios }\end{array}$ & $\begin{array}{l}\text { IG } \\
\text { Médio }\end{array}$ & Mediana & Mín. & Máx. & $\begin{array}{l}\text { Desvio } \\
\text { Padrão }\end{array}$ & $\begin{array}{l}\text { Coeficiente de Variação } \\
\text { (\%) }\end{array}$ \\
\hline Sertão dos Crateús & 13 & 0,41 & 0,37 & 0,26 & 0,63 & 0,12 & 29,36 \\
\hline Cariri & 29 & 0,40 & 0,32 & $\underline{0,11}$ & 0,95 & 0,19 & 48,37 \\
\hline Grande Fortaleza & 19 & 0,39 & 0,32 & $\overline{0,21}$ & $\underline{1,00}$ & 0,21 & 54,14 \\
\hline Sertão dos Inhamus & 5 & 0,38 & 0,37 & 0,16 & 0,68 & 0,19 & 50,46 \\
\hline Litoral Norte & 13 & 0,36 & 0,37 & $\underline{0,11}$ & 0,53 & 0,11 & 31,46 \\
\hline Litoral Leste & 6 & $0,35^{*}$ & 0,34 & $\overline{0,16}$ & 0,58 & 0,14 & 38,73 \\
\hline Maciço de Baturité & 13 & $0,35^{*}$ & 0,37 & 0,21 & 0,58 & 0,11 & 30,12 \\
\hline Serra da Ibiapaba & 9 & $0,35^{*}$ & 0,37 & 0,21 & 0,58 & 0,10 & 29,05 \\
\hline $\begin{array}{l}\text { Litoral Oeste / Vale do } \\
\text { Curu }\end{array}$ & 12 & 0,33 & 0,34 & 0,16 & 0,53 & 0,10 & 31,36 \\
\hline Sertão Sobral & 18 & 0,32 & 0,26 & 0,16 & 0,84 & 0,20 & 61,83 \\
\hline Centro Sul & 13 & $0,31^{*}$ & 0,26 & 0,16 & 0,47 & 0,11 & 36,18 \\
\hline Sertão de Canindé & 6 & $0,31 *$ & 0,29 & 0,21 & 0,42 & 0,08 & 25,23 \\
\hline Sertão Central & 13 & 0,28 & 0,21 & 0,16 & 0,47 & 0,12 & 42,14 \\
\hline CEARÁ & 184 & 0,35 & 0,33 & 0,18 & 0,66 & 0,14 & 39,85 \\
\hline
\end{tabular}

* Nas regiões de planejamento com mesmo IG os critérios de desempate foram: 1ㅇ) maior mediana, 2ㅇ) maior valor mínimo e 3ㅇ) maior valor máximo.

Dentre as 19 disponibilidades investigada para o índice de gestão, o Ceará apresentou uma média de $35 \%(I G=0,35)$ quanto à gestão ambiental, considerando implementações na área de recursos hídricos, como legislação ou instrumento de gestão de bacias hidrográficas; adaptação e mitigação de mudança de clima; ações/iniciativas que promovam a conservação e a recuperação ou melhoramento da quantidade e da qualidade dos recursos hídricos e condições climáticas extremas (enchente ou seca). Embora as regiões de planejamento Sertão do Crateús e Cariri tenham expressado um IG superior à média do estado, ainda assim, todos os resultados apresentam um baixo desenvolvimento de gestão.

Além disso, é importante destacar outras considerações, como no caso das regiões de planejamento Cariri e Litoral Norte onde foi constatada a existência de municípios com baixíssima gestão ambiental (Mínimo $=0,11$ ) enquanto a região de planejamento da Grande Fortaleza apresentou municípios com amplo e total uso de todos os instrumentos de gestão ambiental (Máximo $=1,00$ ), representado pela capital cearense.

O baixo grau de desenvolvimento de gestão no Estado, através de suas regiões de planejamento deve 
ser colocado, de forma preocupante, e até mesmo como um problema regional; uma vez que todo extrato de dados aqui apresentado não se sobressai ao ponto de mudar sua caraterização nem mesmo para médio baixo desenvolvimento de gestão.

É relevante ressaltar que em nenhum município abrangido nas regiões de planejamento do estado do Ceará sequer adote uma estrutura organizacional de gestão ambiental dentre os instrumentos avaliados, fato observado a partir da análise da coluna "Máximo" da Tabela 1.

Dentre os indicadores analisados se tem a caracterização da gestão ambiental, em que em todos os municípios do estado do Ceará possuem órgão gestor para desempenhar competências nas questões ambientais e de recursos hídricos; exceto o município de Martinópole que não possui nenhuma estrutura $(0,55 \%)$ de gestão para trabalhar tais questões.

As estruturas de gestão que caracterizam o estado do Ceará são: $(63,5 \%)$ formação de uma secretaria em conjunto com outras políticas setoriais; $(25 \%)$ secretaria exclusiva; $(6,5 \%)$ setor subordinado a outra secretaria; $(3,26 \%)$ órgão da administração indireta e $(1,2 \%)$ setor subordinado à chefia do executivo.

O órgão gestor são caracterizados por funcionários estatutários em sua maioria entre nas regiões da Grande Fortaleza, Cariri e Sertão Sobral, estas que ainda apresentam em seu quadro gestor, a figura dos estagiários. Dentre as regiões não aparecem funcionários celetistas e cargos comissionados.

A tabela 2, mostra também que todas as regiões de planejamento possuem entre os seus municípios algum deles, o Conselho Municipal do Meio Ambiente, ressaltar um dado especial em que a região da Serra da Ibiapaba, 100\% dos seus municípios possuem conselhos, seguido da Grande Fortaleza (89\%), Vale do Jaguaribe (87\%), Maciço de Baturité e Litoral Norte, ambos (85\%) e Litoral Oeste $(85 \%)$, onde todos eles possuem aproximadamente de 6 a 12 reuniões periódicas por ano.

Todas as regiões de planejamento dispõe de algum recurso financeiro específico para serem utilizados no desenvolvimento de suas ações voltadas para a gestão ambiental e, a maioria dos municípios apresentaram possuir um Fundo de Municipal do Meio Ambiente ou similar, em que as regiões que possuem o maior número de municípios (>60\%) possuem o fundo, exceto Sertão dos Inhamus, Sertão de Canindé e Litoral Leste; valendo ainda ressaltar que nenhuma região de planejamento recebeu desembolso do tesouro estadual para qualquer instrumentalização de gestão.

Com relação a legislação ou instrumentos de controle e monitoramento acerca dos recursos hídricos, temos que a região do Maciço do Baturité $(23 \%)$ possui a maior gestão de bacias hidrográficas e que as regiões do Litoral Leste e Sertão de Canindé (0\%) não possui nenhuma gestão de bacias. Quanto as ações e adaptação e mitigação de mudança do clima, apenas o Litoral Leste (17\%) apresentou possuir algum tipo de instrumento de regulamentação.

Legislação ou instrumento quanto a serviços ambientais acerca de pagamento por ações/iniciativas que promovam a conservação e a recuperação ou melhoramento da quantidade e da qualidade dos recursos hídricos, nenhuma região de planejamento se mostrou relevante.

Legislação ou instrumento quanto à impactos ambientais e/ou processos/ações de maior ocorrência em relação a condições climáticas extremas (secas, enxurradas) e vazão do corpo d'água, em média $60 \%$ das 
regiões de planejamento se preocupam em regulamentar quanto aos impactos ambientais, considerando que a que mais de instrumentaliza é a região de Sertão dos Crateús (85\%) para condições climáticas e a região Centro Sul (46\%) para vazão do corpo d'água.

Tabela 2: Proporção de municípios com implementação de componentes de gestão - IG, por região de planejamento (2017).

\begin{tabular}{|c|c|c|c|c|c|c|c|c|c|c|c|c|c|c|c|c|c|c|}
\hline Região & KKO & KKO & KKO & KKO & KKO & KKO & KKO & KKO & KKO & KKO & KKO & KKO & КKO & KKO & KKO & KKO & КKO & KKO \\
\hline Planejamento & 02 & 03 & 04 & 05 & 06 & 07 & 08 & 09 & 10 & 11 & 12 & 13 & 14 & 15 & 16 & 17 & 18 & 19 \\
\hline Cariri & $34 \%$ & $34 \%$ & $0 \%$ & $7 \%$ & $7 \%$ & $7 \%$ & $21 \%$ & $86 \%$ & $76 \%$ & $21 \%$ & $21 \%$ & $59 \%$ & $17 \%$ & $7 \%$ & $0 \%$ & $10 \%$ & $83 \%$ & $14 \%$ \\
\hline Centro Sul & $8 \%$ & $8 \%$ & $0 \%$ & $0 \%$ & $0 \%$ & $8 \%$ & $15 \%$ & $62 \%$ & $38 \%$ & $8 \%$ & $23 \%$ & $23 \%$ & $8 \%$ & $0 \%$ & $0 \%$ & $8 \%$ & $69 \%$ & $46 \%$ \\
\hline Grande Fortaleza & $21 \%$ & $11 \%$ & $16 \%$ & $32 \%$ & $16 \%$ & $5 \%$ & $26 \%$ & $95 \%$ & $89 \%$ & $53 \%$ & $47 \%$ & $79 \%$ & $16 \%$ & $16 \%$ & $0 \%$ & $0 \%$ & $16 \%$ & $16 \%$ \\
\hline Litoral Leste & $0 \%$ & $0 \%$ & $0 \%$ & $0 \%$ & $0 \%$ & $0 \%$ & $15 \%$ & $92 \%$ & $85 \%$ & $38 \%$ & $54 \%$ & $62 \%$ & $15 \%$ & $0 \%$ & $0 \%$ & $8 \%$ & $54 \%$ & $23 \%$ \\
\hline Litoral Norte & $0 \%$ & $0 \%$ & $0 \%$ & $0 \%$ & $0 \%$ & $17 \%$ & $33 \%$ & $92 \%$ & $83 \%$ & $17 \%$ & $33 \%$ & $33 \%$ & $17 \%$ & $17 \%$ & $0 \%$ & $0 \%$ & $67 \%$ & $25 \%$ \\
\hline $\begin{array}{l}\text { Litoral Oeste / Vale } \\
\text { do Curu }\end{array}$ & $0 \%$ & $0 \%$ & $0 \%$ & $0 \%$ & $0 \%$ & $17 \%$ & $33 \%$ & $92 \%$ & $83 \%$ & $17 \%$ & $33 \%$ & $33 \%$ & $17 \%$ & $17 \%$ & $0 \%$ & $0 \%$ & $67 \%$ & $25 \%$ \\
\hline Maciço de Baturité & $8 \%$ & $0 \%$ & $0 \%$ & $0 \%$ & $0 \%$ & $15 \%$ & $8 \%$ & $92 \%$ & $85 \%$ & $8 \%$ & $54 \%$ & $23 \%$ & $23 \%$ & $8 \%$ & $0 \%$ & $0 \%$ & $62 \%$ & $38 \%$ \\
\hline Serra da Ibiapaba & $11 \%$ & $0 \%$ & $22 \%$ & $0 \%$ & $0 \%$ & $0 \%$ & $0 \%$ & $\begin{array}{l}100 \\
\%\end{array}$ & $\begin{array}{l}100 \\
\%\end{array}$ & $22 \%$ & $33 \%$ & $56 \%$ & $11 \%$ & $0 \%$ & $0 \%$ & $11 \%$ & $56 \%$ & $33 \%$ \\
\hline Sertão Central & $0 \%$ & $0 \%$ & $0 \%$ & $0 \%$ & $0 \%$ & $15 \%$ & $15 \%$ & $62 \%$ & $46 \%$ & $8 \%$ & $23 \%$ & $8 \%$ & $8 \%$ & $0 \%$ & $0 \%$ & $0 \%$ & $69 \%$ & $23 \%$ \\
\hline Sertão Canindé & $0 \%$ & $0 \%$ & $0 \%$ & $0 \%$ & $0 \%$ & $0 \%$ & $17 \%$ & $\begin{array}{l}100 \\
\%\end{array}$ & $67 \%$ & $0 \%$ & $67 \%$ & $33 \%$ & $0 \%$ & $0 \%$ & $0 \%$ & $0 \%$ & $67 \%$ & $17 \%$ \\
\hline Sertão Sobral & $17 \%$ & $11 \%$ & $0 \%$ & $11 \%$ & $17 \%$ & $28 \%$ & $22 \%$ & $67 \%$ & $33 \%$ & $33 \%$ & $28 \%$ & $22 \%$ & $6 \%$ & $0 \%$ & $0 \%$ & $0 \%$ & $39 \%$ & $17 \%$ \\
\hline Sertão dos Crateús & $0 \%$ & $0 \%$ & $0 \%$ & $0 \%$ & $0 \%$ & $15 \%$ & $8 \%$ & $\begin{array}{l}100 \\
\% \\
\end{array}$ & $77 \%$ & $38 \%$ & $54 \%$ & $85 \%$ & $15 \%$ & $8 \%$ & $0 \%$ & $8 \%$ & $85 \%$ & $46 \%$ \\
\hline Sertão dos Inhamus & $0 \%$ & $0 \%$ & $0 \%$ & $0 \%$ & $0 \%$ & $0 \%$ & $0 \%$ & $80 \%$ & $80 \%$ & $40 \%$ & $60 \%$ & $20 \%$ & $20 \%$ & $0 \%$ & $0 \%$ & $0 \%$ & $80 \%$ & $20 \%$ \\
\hline Vale do Jagauribe & $0 \%$ & $0 \%$ & $0 \%$ & $0 \%$ & $0 \%$ & $13 \%$ & $13 \%$ & $93 \%$ & $87 \%$ & $7 \%$ & $13 \%$ & $\begin{array}{l}280 \\
\% \\
\end{array}$ & $7 \%$ & $0 \%$ & $0 \%$ & $0 \%$ & $67 \%$ & $33 \%$ \\
\hline
\end{tabular}

O gráfico 1 mostra a situação dos dez melhores e piores municípios em termos de instrumentos de gestão (IG); onde entre os melhores municípios com melhores atuação e organização da gestão ambiental no estado do Ceará, estão respectivamente, Fortaleza, Crato, Maracanaú, Sobral, Juazeiro do Norte, Massapê, Tauá e, empatados como os três últimos melhores está Barbalha, Caririaçu e Independência.

Já os municípios com pior estrutura organizacional de gestão ambiental estão empatados os municípios de Milhã, Moraújo, Pedra Branca, Penaforte, Santana do Acaraú, Senador Sá, Solonópole e Tururu e, em seguida, com os dois piores resultados estão Martinópole e Potengi.

É possível identificar que os municípios com as melhores estruturas de gestão ambiental estão contidos nas regiões de planejamento Grande Fortaleza, Sertão Sobral e Cariri; estas que apresentam o maior número populacional, o maior PIB per capita e o maior número de município entre todo o estado cearense.

E quanto aos piores municípios se percebe pouco investimento na estrutura organizacional da gestão ambiental, de apenas $16 \%$ dentre os indicadores analisados apontam uma gestão ambiental organizada e preocupada com as questões dos recursos hídricos e os impactos adversos como o fenômeno seca.

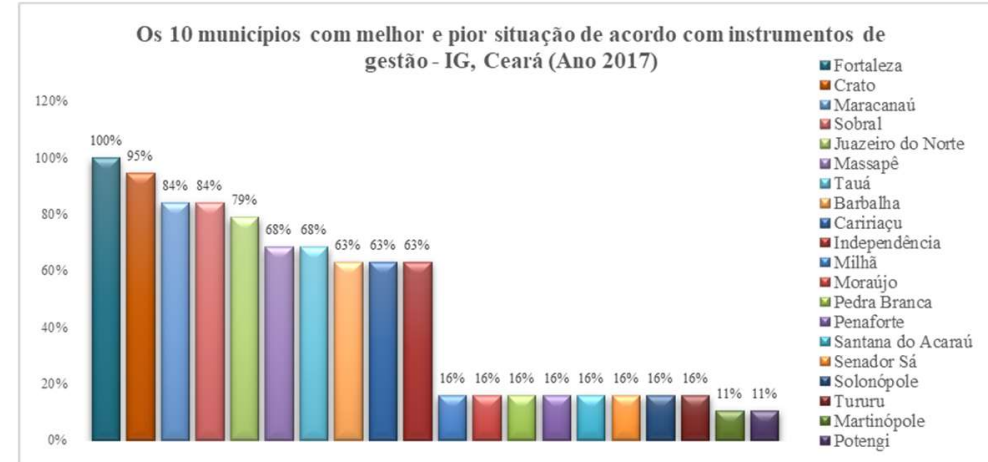

Gráfico 1: Os 10 municípios em melhor e pior situação de acordo com instrumentos de gestão - IG, Ceará (2017). 
O ranking por região de planejamento apresentado no gráfico 2 configura e posiciona o estado cearense de forma diferente de quando analisado os municípios isoladamente. Enquanto que no gráfico 1, as regiões de planejamento Grande Fortaleza, Cariri e Sertão Sobral, por meio de algum dos seus municípios ganham força e predominância em estrutura organizada na gestão ambiental, no gráfico 2 quando agrupados todas as variáveis que envolve o órgão gestor e de instrumentos e legislação acerca dos recursos hídricos juntamente com as ações/iniciativas que promovam a conservação e recuperação da quantidade e qualidade do mesmo e os impactos ambientais ocorridos por condições climáticas extremas, é apresentado o Vale do Jaguaribe (43\%) como a melhor região de planejamento em gestão ambiental, quando analisado o seu conjunto de municípios.

Já as regiões de planejamento Cariri, Grande Fortaleza e Sertão Sobral se encontram em posições no ranking de 3a , 4a e 11a , respectivamente, como mostra o gráfico 2 . Esse resultado revela que ao agrupar os municípios de cada região, os instrumentos de gestão estão concentrados apenas nas cidades de fluxo econômico, PIB per capita, número populacional alto; as quais são Crato, Fortaleza e Sobral, deixando os outros municípios destas regiões sem um mínimo de estrutura de gestão capaz de implementar instrumentos reguladores de políticas ambientais e de recursos hídricos.

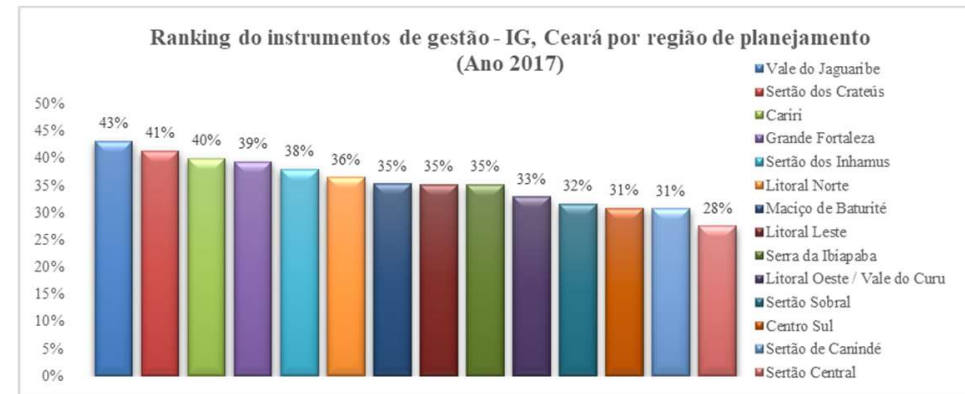

Gráfico 2: Ranking do instrumento de gestão - IG, Ceará, por região de planejamento (2017).

\section{Índice de Gestão à Seca - IGS}

O índice de gestão à Seca trata da identificação de impactos e adoção de medidas de gestão pública voltados para o com o evento seca, contemplando variáveis como os impactos que atinge os municípios com perdas financeiras, de animais, humanas, ambientais, produção agrícola, aparecimento de desertificação, concentração de poluentes na água exigindo ampliação na captação e no tratamento da água.

Na tabela 3 podemos verificar a estatística descritiva do índice de gestão à seca, onde podemos observar que o estado do Ceará possui um desvio padrão baixo, indicando que os resultados entre as regiões de planejamento circundam próximos a média. Já o coeficiente de variação, que trata do desvio padrão relativo, uma vez que apenas o resultado do desvio padrão não é o suficiente para caracterizar os dados, expressa um resultado com moderada dispersão (>30\%) apresentando variáveis heterogêneas e categóricas de se fazer análises comparativas entre a variação de dados observados.

Dentre as 17 disponibilidades investigada para o índice de gestão, o Ceará apresentou uma média de $64 \%(I G=0,64)$ quanto ao diagnóstico de impactos e adoção de medidas à seca, considerando riscos e implementações no que diz respeito aos recursos hídricos e abrangências de convivência ao semiárido, 
significando um posicionamento médio baixo de desenvolvimento da gestão.

Tabela 3: Estatísticas descritivas do IGS, por região de planejamento do Ceará (2017).

\begin{tabular}{|c|c|c|c|c|c|c|c|}
\hline Região de Planejamento & $\begin{array}{ll}\text { Total } & \text { de } \\
\text { Municípios } & \\
\end{array}$ & $\begin{array}{l}\text { IGS } \\
\text { Médio }\end{array}$ & Mediana & Mínimo & Máximo & $\begin{array}{l}\text { Desvio } \\
\text { Padrão }\end{array}$ & $\begin{array}{l}\text { Coeficiente de Variação } \\
\text { (\%) }\end{array}$ \\
\hline Centro Sul & 13 & 0,78 & 0,82 & 0,59 & 0,94 & 0,11 & 14,51 \\
\hline Sertão Central & 13 & 0,74 & 0,76 & 0,06 & 0,94 & 0,22 & 30,34 \\
\hline Sertão dos Inhamus & 5 & 0,72 & 0,65 & 0,59 & 0,88 & 0,13 & 17,77 \\
\hline Litoral Oeste / Vale do Curu & 12 & 0,71 & 0,76 & 0,06 & $\underline{1,00}$ & 0,25 & 35,57 \\
\hline Cariri & 29 & 0,69 & 0,71 & 0,47 & $\overline{0,94}$ & 0,11 & 16,26 \\
\hline Vale do Jaguaribe & 15 & 0,67 & 0,65 & 0,41 & $\underline{1,00}$ & 0,15 & 21,83 \\
\hline Serra da Ibiapaba & 9 & $0,65 *$ & 0,65 & 0,35 & 0,88 & 0,16 & 24,83 \\
\hline Sertão de Canindé & 6 & $0,65^{*}$ & 0,65 & 0,24 & $\underline{1,00}$ & 0,26 & 40,66 \\
\hline Litoral Leste & 6 & $0,63 *$ & 0,65 & 0,35 & $\overline{0,88}$ & 0,20 & 31,19 \\
\hline Sertão dos Crateús & 13 & $0,63^{*}$ & 0,59 & 0,24 & 1,00 & 0,18 & 28,92 \\
\hline Sertão Sobral & 18 & 0,57 & 0,59 & 0,06 & $\overline{0,82}$ & 0,18 & 32,01 \\
\hline Grande Fortaleza & 19 & 0,56 & 0,53 & $\underline{0,00}$ & 0,94 & 0,25 & 44,97 \\
\hline Litoral Norte & 13 & 0,54 & 0,53 & $\overline{0,29}$ & 0,88 & 0,16 & 29,39 \\
\hline Maciço de Baturité & 13 & 0,45 & 0,59 & $\underline{0,00}$ & 0,71 & 0,23 & 50,72 \\
\hline CEARÁ & 184 & 0,64 & 0,65 & $\overline{0,27}$ & 0,92 & 0,19 & 29,93 \\
\hline
\end{tabular}

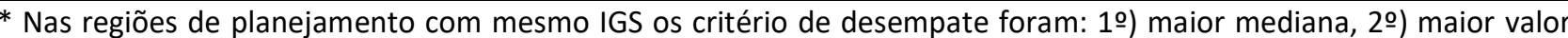
mínimo e 3의) maior valor máximo.

É relevante ressaltar que em quatro regiões de planejamento, Litoral Oeste/Vale do Curu, Vale do Jaguaribe, Sertão Canindé e Sertão dos Crateús, apresentando municípios entre estas regiões com amplo e total uso de todos os instrumentos de gestão ambiental (Máximo $=1,00$ ) e, já, em outras regiões como Maciço de Baturité e Grane Fortaleza foi constatada a existência de municípios com baixíssima gestão ambiental (Mínimo =0,00), ou seja, não há sequer um município que adote alguma medida à seca.

Em quase todas as regiões de planejamento, os municípios foram atingidos pela seca nos últimos 4 anos em $100 \%$, excetuando a região da Grande Fortaleza que $89 \%$ dos seus municípios foram atingidos e Maciço de Baturité $85 \%$, pela seca. Dentre os municípios afetados o ano em que ocorreu a maior seca foi o ano de 2016. No ano de seca de maior impacto nas regiões de planejamento ocorreram algumas variadas perdas, dentre elas a tabela 4 mostra que considerando todos os municípios cearenses, $88 \%$ destes tiveram perdas financeiras, $7 \%$ perdas humanas, $82 \%$ perdas animais, $78 \%$ perdas ambientais e $94 \%$ perdas na produção agrícola.

É importante ressaltar que no que se trata de perdas humanas as regiões que se apresentaram com maior número de município foram a Grande Fortaleza (21\%) e Sertão Central (38\%). Já todos os municípios das regiões do Litoral Leste e Sertão dos Inhamus tiveram perdas animais, 100\% das cidades das regiões da Serra da Ibiapaba e Inhamus tiveram perdas ambientais e, também em 100\% dos municípios das regiões de Cariri, Centro Sul, Litoral Leste, Litoral Norte, Sertão de Canindé, Sertão dos Inhamus e Vale do Jaguaribe tiveram perdas na produção agrícola.

Quanto ao surgimento ou aumento de área de desertificação e concentração de poluentes na água exigindo ampliação na captação e no tratamento da água; todas as regiões de planejamento apresentaram municípios que sofreram pelo efeito da desertificação, excetuando a Região do Maciço de Baturité.

A tabela 4 ainda revela o que está sendo feito para evitar ou minimizar os danos causados pela seca em que tiveram como maior beneficiada em suas regiões de planejamento: Sertão dos Inhamus (100\%) e 
Cariri (90\%) na construção de cisternas; Centro Sul (62\%) e Sertão Central (69\%) na construção de açudes; Centro Sul (62\%) e Litoral Oeste/Vale do Curu (58\%) na construção de barragens; Cariri (93\%), Litoral Sul e Litoral Norte (92\%), Sertão de Canindé, Sertão dos Crateús e Sertão do Inhamus (100\%) na construções de poços profundos e, por fim Sertão Central (31\%) e Inhamus (40\%) em atividades de revegetação.

Tabela 4: Proporção de municípios com implementação de componentes de gestão à seca - IGS, por região de planejamento (2017).

\begin{tabular}{|c|c|c|c|c|c|c|c|c|c|c|c|c|c|c|c|c|c|}
\hline $\begin{array}{ll}\text { Região } & \text { de } \\
\text { Planejamento } & \\
\end{array}$ & $\begin{array}{l}\text { ELO } \\
01\end{array}$ & $\begin{array}{l}\text { ELO } \\
02\end{array}$ & $\begin{array}{l}\text { ELO } \\
03\end{array}$ & $\begin{array}{l}\text { ELO } \\
04\end{array}$ & $\begin{array}{l}\text { ELO } \\
05\end{array}$ & $\begin{array}{l}\text { ELO } \\
06\end{array}$ & $\begin{array}{l}\text { ELO } \\
07\end{array}$ & $\begin{array}{l}\text { ELO } \\
08\end{array}$ & $\begin{array}{l}\text { ELO } \\
09\end{array}$ & $\begin{array}{l}\text { ELO } \\
10\end{array}$ & $\begin{array}{l}\text { ELO } \\
11\end{array}$ & $\begin{array}{l}\text { ELO } \\
12\end{array}$ & $\begin{array}{l}\text { ELO } \\
13\end{array}$ & $\begin{array}{l}\text { ELO } \\
14\end{array}$ & $\begin{array}{l}\text { ELO } \\
15\end{array}$ & $\begin{array}{l}\text { ELO } \\
16\end{array}$ & $\begin{array}{l}\text { ELO } \\
17\end{array}$ \\
\hline Cariri & $\begin{array}{l}100 \\
\%\end{array}$ & $\begin{array}{l}245 \\
\%\end{array}$ & $97 \%$ & $0 \%$ & $97 \%$ & $90 \%$ & $\begin{array}{l}100 \\
\%\end{array}$ & $28 \%$ & $7 \%$ & $90 \%$ & $28 \%$ & $34 \%$ & $93 \%$ & $17 \%$ & $34 \%$ & $90 \%$ & $17 \%$ \\
\hline Centro Sul & $\begin{array}{l}100 \\
\%\end{array}$ & $\begin{array}{l}231 \\
\%\end{array}$ & $\begin{array}{l}100 \\
\%\end{array}$ & $8 \%$ & $92 \%$ & $85 \%$ & $\begin{array}{l}100 \\
\%\end{array}$ & $46 \%$ & $69 \%$ & $69 \%$ & $62 \%$ & $62 \%$ & $92 \%$ & $23 \%$ & $62 \%$ & $\begin{array}{l}100 \\
\%\end{array}$ & $31 \%$ \\
\hline Grande Fortaleza & $89 \%$ & $\begin{array}{l}159 \\
\%\end{array}$ & $89 \%$ & $21 \%$ & $63 \%$ & $74 \%$ & $79 \%$ & $21 \%$ & $37 \%$ & $53 \%$ & $21 \%$ & $32 \%$ & $74 \%$ & $21 \%$ & $21 \%$ & $89 \%$ & $21 \%$ \\
\hline Litora & $\begin{array}{l}100 \\
\%\end{array}$ & $\begin{array}{l}200 \\
\%\end{array}$ & $\begin{array}{l}100 \\
\%\end{array}$ & $17 \%$ & $\begin{array}{l}100 \\
\%\end{array}$ & $83 \%$ & $\begin{array}{l}100 \\
\%\end{array}$ & $33 \%$ & $33 \%$ & $67 \%$ & $17 \%$ & $0 \%$ & $83 \%$ & $0 \%$ & $0 \%$ & $\begin{array}{l}100 \\
\%\end{array}$ & $33 \%$ \\
\hline Litor & $\begin{array}{l}100 \\
\%\end{array}$ & $\begin{array}{l}177 \\
\%\end{array}$ & $69 \%$ & $0 \%$ & $54 \%$ & $54 \%$ & $\begin{array}{l}100 \\
\%\end{array}$ & $8 \%$ & $31 \%$ & $69 \%$ & $8 \%$ & $15 \%$ & $92 \%$ & $8 \%$ & $15 \%$ & $\begin{array}{l}100 \\
\%\end{array}$ & $23 \%$ \\
\hline $\begin{array}{l}\text { Litoral Oeste / Vale } \\
\text { do Curu }\end{array}$ & $\begin{array}{l}100 \\
\%\end{array}$ & $\begin{array}{l}200 \\
\%\end{array}$ & $92 \%$ & $0 \%$ & $92 \%$ & $92 \%$ & $92 \%$ & $33 \%$ & $50 \%$ & $83 \%$ & $50 \%$ & $58 \%$ & $75 \%$ & $17 \%$ & $33 \%$ & $83 \%$ & $67 \%$ \\
\hline Mac & $85 \%$ & $\begin{array}{l}218 \\
\%\end{array}$ & $69 \%$ & $8 \%$ & $54 \%$ & $69 \%$ & $85 \%$ & $0 \%$ & $0 \%$ & $69 \%$ & $8 \%$ & $23 \%$ & $54 \%$ & $0 \%$ & $0 \%$ & $69 \%$ & $0 \%$ \\
\hline lbiapaba & $\begin{array}{l}100 \\
\%\end{array}$ & $\begin{array}{l}200 \\
\%\end{array}$ & $\begin{array}{l}100 \\
\%\end{array}$ & $0 \%$ & $89 \%$ & $\begin{array}{l}100 \\
\%\end{array}$ & $89 \%$ & $44 \%$ & $44 \%$ & $67 \%$ & $11 \%$ & $11 \%$ & $89 \%$ & $22 \%$ & $22 \%$ & $78 \%$ & $44 \%$ \\
\hline Sertão Central & $\begin{array}{l}100 \\
\%\end{array}$ & $\begin{array}{l}233 \\
\% \\
\end{array}$ & $85 \%$ & $38 \%$ & $92 \%$ & $85 \%$ & $92 \%$ & $62 \%$ & $46 \%$ & $62 \%$ & $69 \%$ & $31 \%$ & $85 \%$ & $31 \%$ & $38 \%$ & $77 \%$ & $46 \%$ \\
\hline Sertão Canindé & $\begin{array}{l}100 \\
\%\end{array}$ & $\begin{array}{l}250 \\
\%\end{array}$ & $67 \%$ & $0 \%$ & $83 \%$ & $67 \%$ & $\begin{array}{l}100 \\
\%\end{array}$ & $33 \%$ & $33 \%$ & $67 \%$ & $33 \%$ & $17 \%$ & $\begin{array}{l}100 \\
\%\end{array}$ & $17 \%$ & $33 \%$ & $83 \%$ & $17 \%$ \\
\hline Sertão Sobral & $\begin{array}{l}100 \\
\%\end{array}$ & $\begin{array}{l}224 \\
\% \\
\end{array}$ & $83 \%$ & $0 \%$ & $67 \%$ & $56 \%$ & $89 \%$ & $28 \%$ & $28 \%$ & $61 \%$ & $28 \%$ & $11 \%$ & $83 \%$ & $6 \%$ & $17 \%$ & $89 \%$ & $11 \%$ \\
\hline Sertão dos Crateús & $\begin{array}{l}100 \\
\%\end{array}$ & $\begin{array}{l}177 \\
\%\end{array}$ & $92 \%$ & $0 \%$ & $85 \%$ & $77 \%$ & $92 \%$ & $23 \%$ & $31 \%$ & $85 \%$ & $31 \%$ & $31 \%$ & $\begin{array}{l}100 \\
\%\end{array}$ & $15 \%$ & $15 \%$ & $85 \%$ & $31 \%$ \\
\hline Sertão dos Inhamus & $\begin{array}{l}100 \\
\%\end{array}$ & $\begin{array}{l}120 \\
\%\end{array}$ & $\begin{array}{l}100 \\
\%\end{array}$ & $0 \%$ & $\begin{array}{l}100 \\
\%\end{array}$ & $\begin{array}{l}100 \\
\%\end{array}$ & $\begin{array}{l}100 \\
\%\end{array}$ & $80 \%$ & $60 \%$ & $\begin{array}{l}100 \\
\%\end{array}$ & $40 \%$ & $40 \%$ & $\begin{array}{l}100 \\
\%\end{array}$ & $20 \%$ & $40 \%$ & $80 \%$ & $40 \%$ \\
\hline Vale do Jagauribe & $\begin{array}{l}100 \\
\%\end{array}$ & $\begin{array}{l}233 \\
\%\end{array}$ & $93 \%$ & $0 \%$ & $80 \%$ & $7 \%$ & $\begin{array}{l}100 \\
\%\end{array}$ & $40 \%$ & $27 \%$ & $73 \%$ & $47 \%$ & $13 \%$ & $\begin{array}{l}100 \\
\%\end{array}$ & $7 \%$ & $33 \%$ & $\begin{array}{l}100 \\
\%\end{array}$ & $33 \%$ \\
\hline
\end{tabular}

No que está sendo feito no município para evitar ou minimizar os danos causados pela seca quanto ao incentivo público à agricultura adaptada ao clima e solo da região, com sistemas de irrigação, se tem a Grande Fortaleza (62\%) como maior beneficiada; distribuição regular de água através de carros-pipa em épocas de estiagem apresentou-se as regiões de planejamento Litoral Norte e Leste, Vale do Jaguaribe e Centro Sul com $100 \%$ de benefício.

Já o que tem sido realizado para dirimir os danos causado pela seca no tocante às ações de uso sustentável dos recursos naturais (fontes de energia eólica ou solar, planos de bacia, programas de conscientização e sensibilização etc.), se tem o Litoral Oeste/Vale do Curu como o principal beneficiado com $67 \%$ dos seus municípios.

O gráfico 3 mostra a situação dos dez melhores e piores municípios em termos de identificação de impactos e adoção de medidas mitigadoras relacionadas à seca (IGS); onde entre os melhores municípios com melhores atuação da gestão ambiental nesta dimensão no estado do Ceará, estão respectivamente, Apuiarés, Itatira, Jaguaribe, Santa Quitéria, Araripe, Choró, Ibicultinga, Maranguape, Orós, Acopiara. Já os municípios com pior atividade nesta dimensão na adoção de medidas ambientais estão os municípios de 
Barroquinha, Caridade, Hidrolândia, Coreaú, Itapipoca, Sonolópole, Eusébio e, ainda com resultados zerados temos Fortaleza, Guaramiranga e Pacoti.

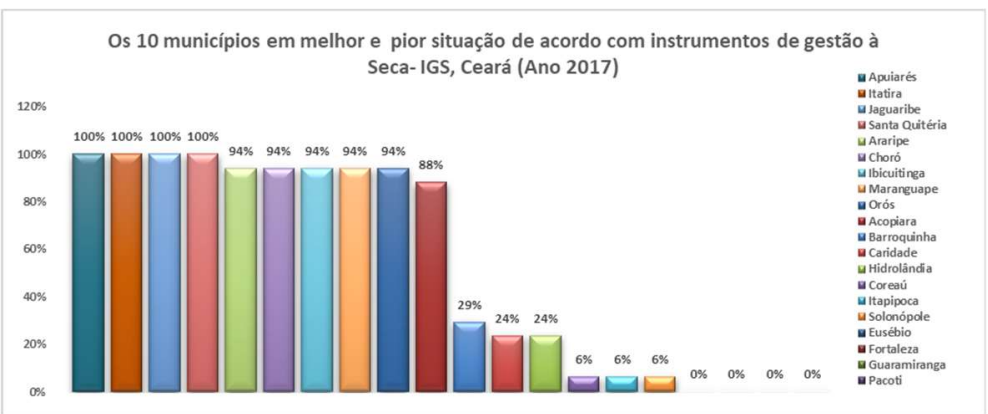

Gráfico 3: Os 10 municípios em melhor e pior situação de acordo com instrumentos de gestão à Seca - IGS, Ceará (2017).

Quanto aos piores municípios se percebe pouco a zero investimento em medidas de mitigação da gestão ambiental quando os impactos são ocasionados pela seca, variando entre $29 \%$ a $0 \%$ dentre os indicadores analisados que apontam uma tomada preocupante com as questões dos recursos hídricos e os impactos adversos como o fenômeno seca.

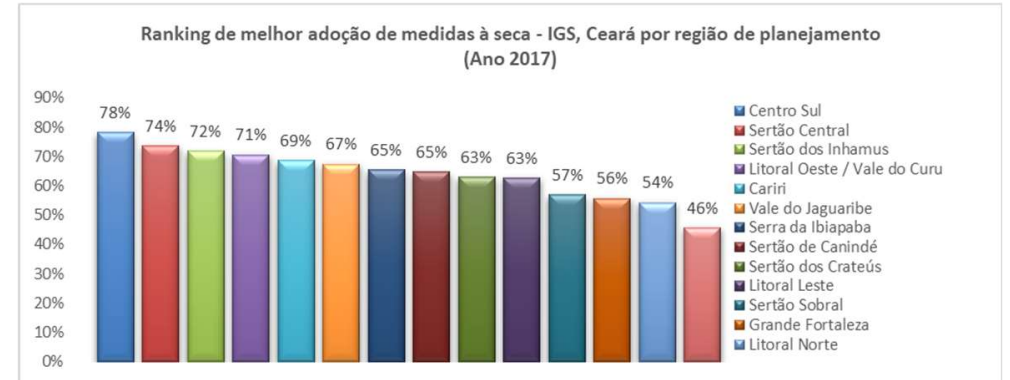

Gráfico 4: Ranking do instrumento de gestão à Seca - IGS, Ceará, por região de planejamento (2017).

O ranking por região de planejamento apresentado no gráfico 4 mostra um resultado positivo com relação a categorização e posicionamento das regiões do estado cearense com relação aos aspectos de adoção de medidas, na qual seu índice geral se enquadrou em 64\% na média, porém verificamos através do gráfico que existem regiões de planejamento como Centro Sul, Sertão Central, Sertão dos Inhamus, Litoral Oeste e Cariri que se posicionaram acima da média do estado.

\section{CONCLUSÕES}

Todas as regiões de planejamento possuem órgão gestor por meio de uma secretaria exclusiva ou setorial em conjunto com outras secretarias formado em sua maioria por representantes estatutários, exceto o município de Martinópole que não apresentou nenhuma estrutura organizacional para desenvolver gestão e políticas ambientais.

Em 100\% da abrangência das regiões de planejamento possuem Conselhos Municipais em meio ambiente com reuniões periódicas de 6 a 12 vezes por ano para tratativas e discussões acerca de regulamentações legislativas e instrumentos de gestão ambiental.

Com relação aos índices, se tem que o índice de gestão possui baixo desenvolvimento e os índice de 
adoção de medidas à seca, médio baixo desenvolvimento em gestão. É importante salientar que o município de Solonópolis obteve um dos piores resultados tanto em índice de gestão quanto em índice de gestão à seca, ou seja, não possuindo instrumento legais e de monitoramento de gestão ambiental, principalmente voltada para os recursos hídricos.

As regiões de planejamento Grande Fortaleza e Maciço de Baturité teve entre os seus municípios (Guaramiranga, Pacoti e Fortaleza) um dos piores resultados quanto ao índice de gestão à seca, corroborando com os seus 12 e e 14 ㅇ lugar no ranking do IGS, respectivamente. Todos os municípios cearenses sofreram com a seca nos últimos quatro anos, tendo o ano de 2016, o ano com maior impacto e perdas humanas, animais, ambientais e de produção agrícola entre as regiões de planejamento.

Sertão do Inhamus é a região de planejamento que possui $100 \%$ dos seus municípios estrutura organizacional preparada e qualificada, mais de $60 \%$ das cidades possuem fundo municipal ao meio ambiente e disposição de recursos financeiros específicos para serem utilizados no desenvolvimento de ações; nos rankings se posiciona em 50 lugar quanto ao índice de gestão e o 3임 lugar no índice de gestão à seca, se classificando em médio alto desenvolvimento da gestão. A região foi beneficiada em $100 \%$ na construção de cisternas e poços profundos e $40 \%$ em revegetação; porém mesmo com todas organização e investimentos voltados a dirimir os efeitos causado pela seca, a região dos Inhamus também foi a mais afetada quanto as perdas financeiras, animais, ambientais e de produção agrícola.

O trabalho conclui que a região de planejamento do Sertão dos Inhamus representa a região melhor estruturada, assistida e mais beneficiada com relação à gestão ambiental voltada para políticas ambientais, principalmente a que diz respeito aos recursos hídricos e gestão de riscos e desastres no que se refere aos efeitos da seca.

\section{REFERÊNCIAS}

ALVARENGA, A. T.; PHILIPPI JÚNIOR, A.; SOMMERMAN, A.; ALVAREZ, A. M. S.; FERNANDES, V.. Histórico, fundamentos filosóficos e teórico-metodológicos da interdisciplinaridade. In: PHILIPPI JUNIOR, A.; SILVA NETO, A.. Interdisciplinaridade em ciência da tecnologia e inovação. Barueri: Manole, 2011.

ASSIS, D. N. C.; RODRIGUES, L. O.. Índice de desenvolvimento Social - IDS 2012-2015. IPECE, 2018.

BHATTACHARYA, S.; DASS, A.. Vulnerability to drought, cyclones and floods in India. Nova Delhi: Winrock International, 2007.

CARVALHO, M. A. R.. Normais Pluviométricos e probabilidade de safra agrícola de sequeiro no Ceará. Fortaleza: Tipografia Íris, 2013.

FREITAS, R.. Regiões metropolitanas: Uma abordagem conceitual. Revista Humanae, Recife, v.1, n.3, 2009.

IPECE. Instituto de Pesquisa e Estratégia Econômica do Ceará. A Regionalização do Estado do Ceará: Uma Proposta de Reformulação. Texto para discussão no 25. 2006.
LIMA, L. C.. Regionalização do Estado do Ceará. In: LIMA, L. C.; MORAIS, J. O.; SOUZA, M. J. N.. Compartimentação Territorial e Gestão Regional do Ceará. Fortaleza: FUNECE, 2014.

MENDONÇA, F.. Impactos socioambientais urbanos Curitiba: UFPR, 2004.

SAMPIERI, R. H.; COLLADO, C. F.; LUCIO, P. B.. Metodología de la investigación. Ciudad de México: McGraw-Hill, 1991.

MELO, J. A. B.; LIMA, E. R. V.; EREIRA R. A.. Abordagem teórico conceitual sobre riscos e perigos e sua manifestação no semiárido brasileiro através da desertificação. Revista OKARA: Geografia em debate, v.2, n.2, p.128-206, 2008

ROSENDO, A. E. Q.. Desenvolvimento de indicadores de vulnerabilidade à seca na região semiárida brasileira. João Pessoa, 2014.

SIEDENBERG, D. R.. Indicadores de desenvolvimento socioeconômico: uma síntese. Desenvolvimento em Questão, v.1, n.1, p.45-71, 2003. 
SILVA, R. M.. Entre o combate à seca e a convivência com o semiárido: transições paradigmáticas e sustentabilidade do desenvolvimento. Tese (Doutorado) - Universidade de Brasília, Brasília, 2006.
WALKER, G. T.. Ceará (Brazil) famines na the general air movement. Beitrait Physic Freinen Atmosphare. Berlim, v.14, p.88-93, 1928.

A CBPC - Companhia Brasileira de Produção Científica (CNPJ: 11.221.422/0001-03) detém os direitos materiais desta publicação. Os direitos referem-se à publicação do trabalho em qualquer parte do mundo, incluindo os direitos às renovações, expansões e disseminações da contribuição, bem como outros direitos subsidiários. Todos os trabalhos publicados eletronicamente poderão posteriormente ser publicados em coletâneas impressas sob coordenação da Sustenere Publishing, da Companhia Brasileira de Produção Científica e seus parceiros autorizados. Os (as) autores (as) preservam os direitos autorais, mas não têm permissão para a publicação da contribuição em outro meio, impresso ou digital, em português ou em tradução. 